\title{
Ressenya
}

\section{Carrera-Sabaté, Josefina; Pons-Moll, Clàudia; Bach Marquès, Jesús (coord.) (2017). L'ensenyament de la pronunciació del català. Eines, recursos, estratègies i experiències. Graó}

Gemma Repiso Puigdelliura

University of California, Los Angeles

grepisopu@ucla.edu

Rebut: 17 de març del 2020

Acceptat: 30 de juny del 2020

Tal com ressalta l'equip editor de L'ensenyament de la pronunciació en català, Josefina Carrera-Sabaté, Clàudia Pons-Moll i Jesús Bach Marquès, l'habilitat oral és primordial per a la integració de nous parlants a la comunitat d'acollida. Tot i així, l'ensenyament de la pronunciació és, moltes vegades, secundari a les classes de segones llengües i sovint s'ensenya a través de la llengua escrita. En aquest sentit, aquest volum és una eina fonamental per obrir un diàleg sobre la incorporació de la fonètica segmental (sons) i suprasegmental (sil-labificació, entonació) en les classes de llengua.

Josefina Carrera-Sabaté és professora titular a la Facultat de Filologia i Comunicació de la Universitat de Barcelona i dirigeix el grup de recerca d'Innovació Docent en Fonètica Catalana (FONCAT), que ha publicat extensament sobre l'adquisició de la fonètica segmental i suprasegmental del català com a segona llengua. Clàudia Pons-Moll és professora agregada de la Facultat de Filologia i Comunicació de la Universitat de Barcelona, és membre de FONCAT i és codirectora del projecte Els sons del català, juntament amb Josefina Carrera-Sabaté. Jesús Bach Marquès està cursant estudis de doctorat en el programa d'Estudis Lingüístics, Literaris i Culturals a la Universitat de Barcelona i s'especialitza en la variació fònica del català com a segona llengua adquirida per parlants anglòfons.

En el capítol 1, Anna Cutillas Romero i Sílvia Llach Carles presenten els resultats d'un estudi fonètic que té com a objectiu entendre els sons que presenten dificultat a l'alumnat de secundària que té com a primera llengua el mandarí o l'àrab. A partir de la hipòtesi d'anàlisi contrastiva (CAH) (Lado, 1957), les autores proposen una llista de paraules que posen de manifest les diferències dels tres sistemes fonètics. Tots dos grups de parlants presenten dificultats en la sonorització de la fricativa sibilant $/ \mathrm{z} /$ en posició intervocàlica, en la realització de les fricatives postalveolars o en la palatalització de la nasal /n/ (nyicris) i la lateral $/ \mathrm{K} /$ (llimones). A més, els sinoparlants lateralitzen la vibrant múltiple $/ \mathrm{r} /$. El fet que aquest estudi mostri les produccions alternatives dels sons per a cada grup de parlants agilitzarà la detecció de produccions divergents en alumnat sinoparlant i araboparlant per part dels docents i professors de llengua.

En el capítol 2, Josefina Carrera-Sabaté i Clàudia Pons-Moll detallen les característiques de l'eina Els sons del català, que té com a objectiu apropar la fonètica catalana a l'alumnat i el professorat a partir de la visualització dels sons del català amb espectrogrames, palatogrames 
i diagrames articulatoris. Tot i que aquesta eina s'usa àmpliament en contextos universitaris, sembla que encara no ha estat adoptada de manera extensa per part de professors de català com a llengua estrangera. Les autores fan una crida a la difusió de l'eina.

En el capítol 3, Josefina Carrera-Sabaté, Pilar Prieto Vives i Roser Güell Isern introdueixen l'eina Guies de pronunciació del català, dirigida a l'aprenentatge de la fonètica segmental i la prosòdia. Per a l'articulació dels sons, l'eina digital proposa exercicis de discriminació auditiva, repetició i producció oral a partir de cançons o dites i refranys. Pel que fa a la pronunciació, el lloc web permet visualitzar les corbes entonatives al mateix temps que s'escolta l'oració.

En el capítol 4, Meghan Armstrong presenta els resultats d'un experiment pilot sobre la producció de la prosòdia per part d'estudiants de català L2 del nord-est dels Estats Units. L'autora descriu les tendències de l'alumnat de català L2 en les realitzacions dels tons fonològics en oracions declaratives i interrogatives seguint les prediccions de Mennen (2015). Els parlants de català L2 presenten transferència en la dimensió sistèmica (p.e. transferència de l'inventari de categories tonals), en la realització fonètica de les categories (p.e. ventall tonal més ampli en el focus correctiu), i tenen dificultats per a unir forma i significat (p.e. preguntes descendents). A més, l'autora presenta un exemple d'aplicació de l'ensenyament de la prosòdia a classe a partir de la inspecció visual dels moviments de la F0.

En el capítol 5, Mercè Calafí Rius, Eva Ocaña Jiménez, Montserrat Segarra Suana i Rosa Vives Camps fan una proposta didàctica per a l'ensenyament dels sons del català a través d'objectes per a infants amb dificultats auditives. La proposta s'emmarca en la teoria de la percepció plurisensorial, que inclou la percepció somatosensorial, la percepció propioceptiva i la percepció visual. Els objectes seleccionats presenten qualitats semblants a les del so que es vol ensenyar, en termes de la tensió, intensitat, durada, espai i moviment de cada so. Per exemple, la bategant múltiple /r/ és representada per un peix, la cua del qual vibra i estimula la producció de l'oclusió múltiple.

En el capítol 6, Andreu Bosch i Rodoreda recull les intervencions de la taula rodona de la I Jornada-taller sobre l'ensenyament de la pronunciació en què van participar membres d'ens públics dirigits a l'aprenentatge de la llengua o a la incorporació de criteris lingüístics a mitjans audiovisuals. En aquest capítol contribueixen Carme Bové, del Consorci per a la Normalització Lingüística; M. José Sánchez, del Servei d'Immersió i Acolliment Lingüístics del Departament d'Ensenyament de la Generalitat de Catalunya, i Marga Hervàs, del Departament d'Assessorament Lingüístic de la Corporació Catalana de Mitjans Audiovisuals. Les primeres dues aportacions detallen les necessitats lingüístiques de les persones nouvingudes i les activitats dirigides a l'aprenentatge de les habilitats orals. Pel que fa als mitjans audiovisuals, tot i que els professionals de l'àmbit són usuaris competents en català, sovint es fan correccions en l'obertura de les vocals, la neutralització de les vocals àtones, la sonorització de les fricatives i la producció de la palatal lateral.

Aquest volum promou la col-laboració i la interdisciplinarietat entre la recerca i la pedagogia en el camp de l'adquisició de la pronunciació. Això fa que, durant la lectura dels sis capítols, tant professors com investigadors puguin guanyar noves perspectives sobre l'adquisició del sistema segmental i suprasegmental del català. La combinació de contribucions de diversos àmbits apropa els fonaments teòrics i aplicacions pràctiques a docents; i les necessitats i experiències didàctiques a investigadors universitaris. A més, aquesta edició demostra que els recursos per a l'adquisició de la pronunciació del català no només són necessaris en les aules del català com a segona llengua dins del territori, sinó també en aules de català a l'exterior, centres de desenvolupament de la llengua per a infants amb dificultats auditives i professionals de la comunicació. Tot i així, el fet que no es presentin resultats d'adquisició a partir de les eines en línia (Els sons del català o les Guies de pronunciació) és simptomàtic de la feble relació entre l'àmbit de la recerca i l'àmbit de l'ensenyament del català fora de la universitat. 
En aquest sentit, els lectors d'aquesta publicació es podrien haver enriquit amb mostres de guies didàctiques específiques per a la utilització dels recursos digitals adreçats a la instrucció de la pronunciació. Finalment, aquest volum obre noves línies de recerca en l'adquisició de la pronunciació i, específicament, en el desenvolupament de la prosòdia, una àrea que encara no ha rebut suficient atenció i que, tanmateix, és cabdal per a la transmissió de significat.

\section{Bibliografia}

Lado, R. (1957). Linguistics Across Cultures. The University of Michigan Press.

Mennen, I. (2015). Beyond segments: Towards a L2 intonation learning theory. Delais-Roussarie, E., Avanzi, M., Herment, S. (eds.). Prosody and language in contact. Springer, p. 171-188. 
